\title{
Characterisation of plasticity response for reciprocating sliding wear test of Ti-6Al-4V under variables number of cycles
}

\author{
D. Harun ${ }^{\mathrm{a}, 1}$, D.Nalatambi ${ }^{\mathrm{a}, 2}$, R. Md.Nasir ${ }^{\mathrm{b}, 3}$, A.L. Mohd Tobi ${ }^{\mathrm{a}, 4}$ \\ ${ }^{a}$ Faculty of Mechanical and Manufacturing Engineering, \\ Universiti Tun Hussein Onn Malaysia, Batu Pahat, Malaysia. \\ bUSM School of Mechanical Engineering, Universiti Sains Malaysia (Engineering Campus) \\ Seri Ampangan 14300 Nibong Tebal Seberang Perai Selatan, Pulau Pinang, Malaysia \\ 1'dalila@uthm.edu.my, 20 davendran_dave@yahoo.com, ${ }^{3}$ meramdziah@eng.usm.my, \\ 4abdlatif@uthm.edu.my
}

Keywords: Plasticity, reciprocating wear test, pin-on-flat tester, variable number of cycles.

\begin{abstract}
Reciprocating sliding wear test of uncoated titanium alloy, Ti-6Al-4V is investigated using pin-on-flat contact arrangement of Ti-6Al-4V/Ti-6Al-4V pair under variable number of cycles at low number of cycles. The worn surfaces of the titanium alloy specimens were analyzed with the use of optical microscope (2D and 3D OM) and Vickers Hardness analysis was carried on. The pattern of the wear scar characteristics determined and the finding at the end of wear track had been focus through the presence at the end of wear track. It is suggesting an evidence of plastic deformation with the increasing in hardness value. The increase in hardness value at the end of wear track indicates increase in the plastic deformation with increasing number of cycles.
\end{abstract}

\section{Introduction}

Titanium alloy exhibit a good properties in industrial applications due to its excellent of corrosion resistance at high temperatures, good fatigue strength, elevated mechanical resistance together with a low density and the application are widely use for aerospace and aeronautical due to their high strength to weight ratio [1-2]. Poor tribological properties of Ti and its alloys can be attributed to two main factors which are the low resistance to plastic shearing and the low workhardening and the low protection exerted by the surface oxide [4]. Surface damage produce by fretting wear including type of partial slip and gross slip shows results on several wear mechanisms such as corrosion, adhesion and abrasion [2,4] and the reciprocating in back and forth action is underlying material to oxidation and corrosion [5].

Kapoor and Franklin [6] explained in details on the basic mechanism and one of it is leading the progressive extrusion of material. On repeated sliding, high contact pressure areas traverse the surface causing the material to compress in the depth direction and extrude out from the sides and there is an accumulation of shear strain for reversing plastic strains. The contact pressure applying to the wear test give significant features towards the mechanism involved. It is increase at the center of the contact with cycling [7] and for most contact pressure is effect of material removal that gives rise to cyclic plasticity and hence significant accumulation of plastic strain. The present study is an extension of previous similar studies [8], however, characterizes the wear under reciprocating sliding wear conditions with variable low number of cycles at initiation period of wear on the flat bar specimen unlike the previous studies where flat bar specimen was applied with variable number of normal load. Thus, the wear mechanisms of Ti-6Al-4V alloy were extensively studied using the pin-on-flat configuration.

\section{Material and experimental details}

\section{Specimen and materials}

Both type of specimen which are contact pressure/pin and flat bar is titanium alloy, Ti-6Al-4V. It has good properties in excellent combination of high specific strength (strength-to-weight ratio) at elevated temperature, fracture resistant characteristics, and their exceptional resistance to corrosion [2]. The composition consists in the specimen is tabulated in Table 1. The specimen machined into 
two different shapes (i) rectangular flat bar with dimensions of $100 \mathrm{~mm}$ x $25 \mathrm{~mm} \times 8 \mathrm{~mm}$ and (ii) cylindrical pin of $\varnothing 6.5 \mathrm{~mm}$ and $12 \mathrm{~mm}$. Surface roughness prior to testing is $R a=0.2 \mu \mathrm{m}$.

Table 1: Composition of Ti-6Al-4V for both specimen, contact pressure/pin and flat bar

\begin{tabular}{lcccccccc}
\hline Elements & $\mathrm{N}$ & $\mathrm{C}$ & $\mathrm{H}$ & $\mathrm{Fe}$ & $\mathrm{O}$ & $\mathrm{Al}$ & $\mathrm{V}$ & $\mathrm{Ti}$ \\
\hline Weight $\%$ & 0.05 & 0.08 & 0.125 & 0.4 & 0.2 & $5.5-6.75$ & $3.5-4.5$ & Balance \\
\hline
\end{tabular}

\section{Tribological test}

The arrangement for the wear test as shown in Fig. 1 and it is done using the tribometer pin-on-flat machine, (model, TR-20, by Ducom Triboinnovaters, Universiti Sains Malaysia) connected to computer monitoring with linear reciprocating slider. The cylindrical pin was set to be static body while the flat rectangular bar is moving. The test was done in dry condition at ambient air with room temperature, $25^{\circ} \mathrm{C}$ and normal humidity $85 \%$ with three various number of low cycle applied on the cylindrical pin through lever system of 5, 10 and 20 cycle. Constant parameter set up at 100 rpm sliding speed with $20 \mathrm{~kg}$ of applied normal load. The reciprocating sliding displacement setup was $60 \mathrm{~mm}$. The surface of the sample was cleaned by ethanol using a soft cotton cloth to remove any possible contaminations $[9,10]$.

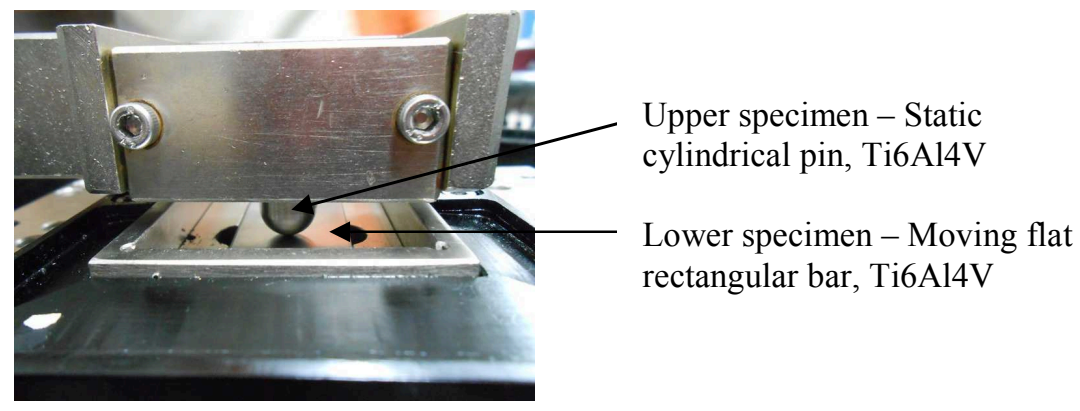

Fig. 1: Configuration of pin-on-flat wear test

Each wear scar is examined by observing it with 2D and 3D optical microscope (OM) to identify the morphology of each of wear scar on the wear track. The result is presented in surface profilometry of the wear scar. The hardness of the wear region is determined by Micro Vicker's hardness-tester, set at load of $980.7 \mathrm{mN}$ (HV0.1) indented to the surface for 5 seconds at three different areas which are original surface, wear track and end of wear track according to ASTM E384 standard.

\section{Result and discussion}

\section{Coefficient of friction}

Data in Fig. 2 shows the relationship between coefficient of friction (COF) and the relative time, $s$. The value of COF for both contact pressure are identified slightly different where at $\varnothing 6.5 \mathrm{~mm}$ pin is 0.30 and $\varnothing 12 \mathrm{~mm}$ pin is 0.34 . The common features for both graphs are exhibited high peak at $1 \mathrm{~s}$ due to static friction. The bodies contact tried to initiate the sliding wear and cause a high frictional force to begin compared to maintain the sliding motion. When there is a contact between Ti6Al4V/Ti6Al4V, the COF decrease and then maintain proportionally with the increase of time. Luo et al. [11] and Johnson [12] proved the results with friction coefficient excess than 0.25 and less than 0.5 in the presence of plastic deformation. 

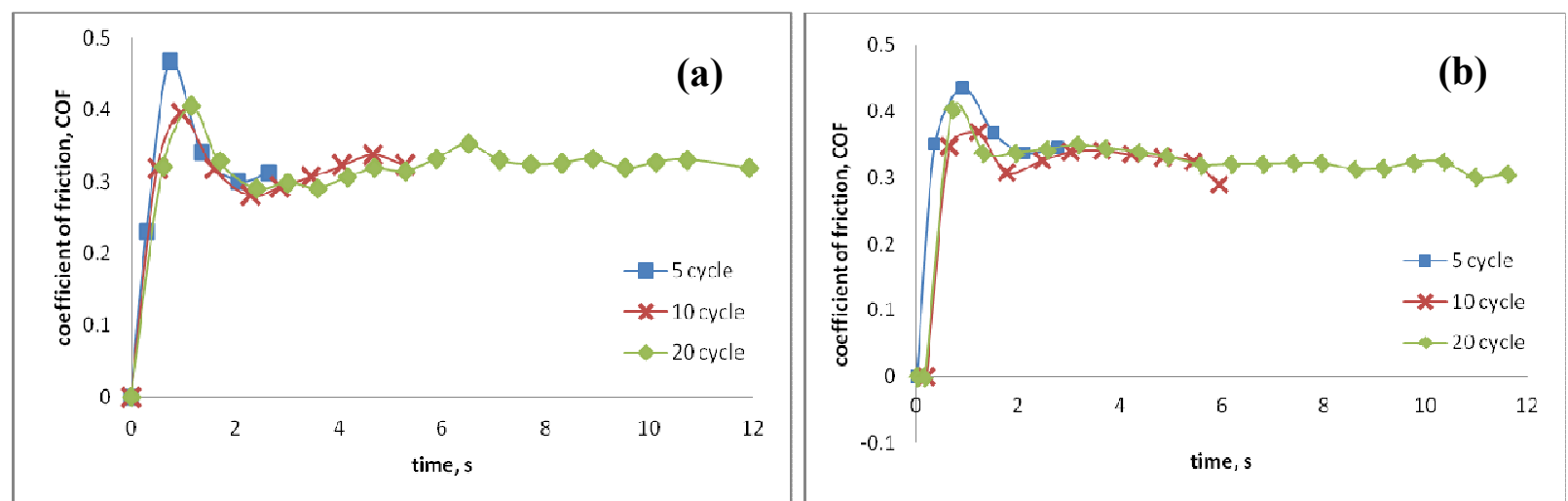

Fig. 2: Evolution of coefficient of friction for variable number of cycles (a) contact pressure with $\varnothing 6.5 \mathrm{~mm} /$ pin and (b) $\varnothing 12 \mathrm{~mm} /$ pin under reciprocating sliding wear regime.

\section{Wear scar characteristics}

The plan view, top view and isometric view for the specimen across the wear track generated by [8] was same used through this experiment. Fig. 3(a) shows the OM image on plan view and Fig. 3(b) shows the cross section view. Wear scar profilometry observed through $2 \mathrm{D}$ and $3 \mathrm{D}$ optical microscope and the determination of wear width of the track was identified.
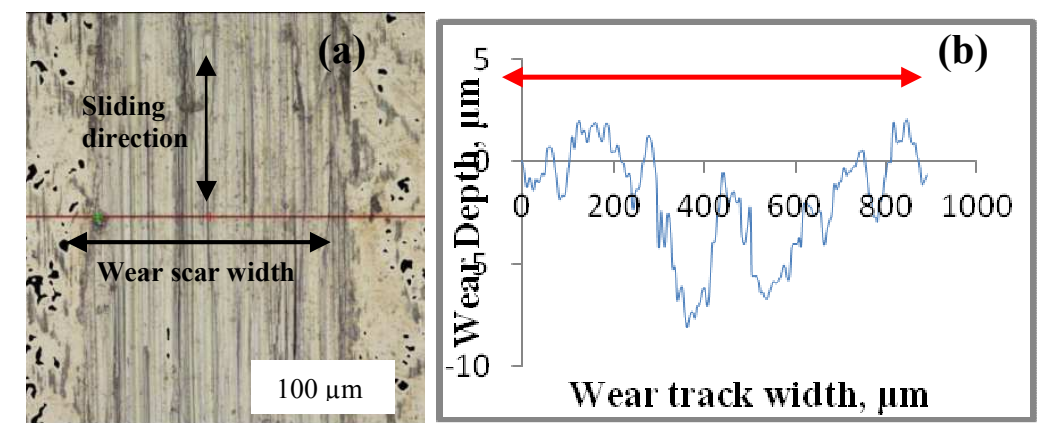

Fig. 3: (a) Optical microscope image on plan view across the wear track for 20 cycles, $\varnothing 12 \mathrm{~mm}$ pin and (b) Plotted graph for wear scar width and depth.

The reciprocating sliding wear shows $\mathrm{W}$-shaped wear scar profile, which also has been obtained by other authors for gross sliding fretting wear of Ti-6Al-4V [13,14]. Those wear scar changes depending on the sliding conditions and particularly W-shaped gradually evolves to U-shaped for the largest amplitude [15].
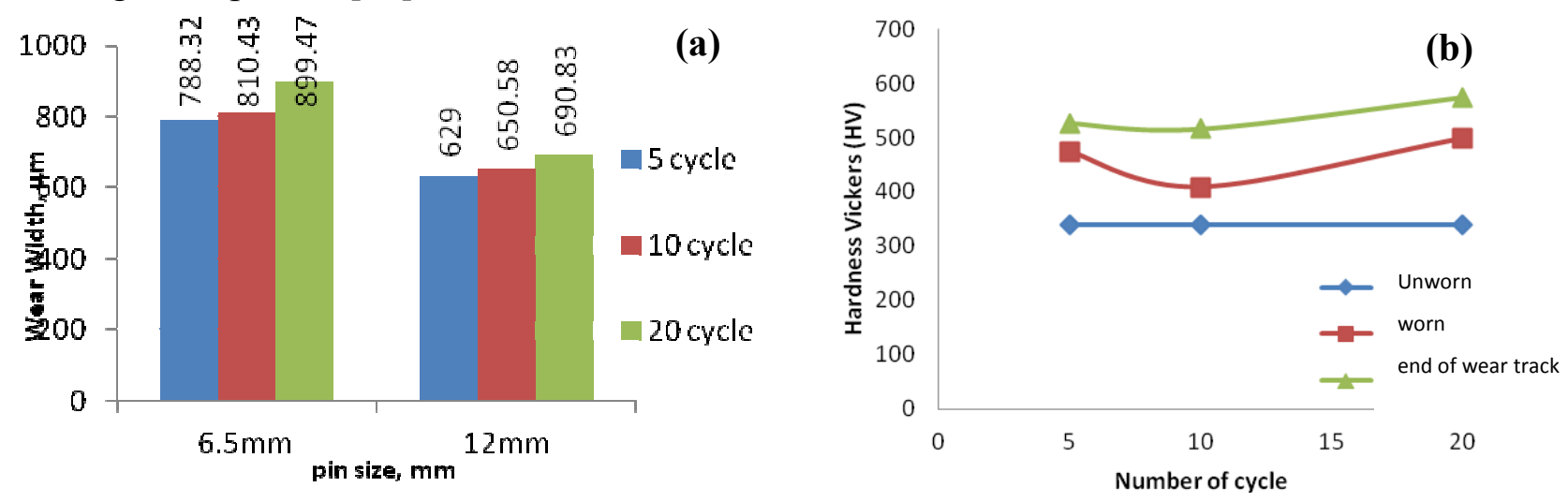

Fig. 4: (a) Graphical data wear width for both pin sizes and (b) Vickers Hardness value on three regions of flat specimen Ti-6Al-4V for different number of cycles with pin size of $\varnothing 12 \mathrm{~mm}$.

Fig. 4 (a) shows result for the wear width on three different numbers of cycles with both pin sizes. The increase of wear width is slightly increased with the increasing of numbers of cycles and this trend is the same as that predicted by Everitt et. al [16]. Wear width value for pin size of $\varnothing 6.5 \mathrm{~mm}$ 
is higher than pin size of $\varnothing 12 \mathrm{~mm}$. Kapoor et. al [6] reported for the repeated sliding these high contact pressure areas traverse the surface causing the material to compress in the depth direction and extrude out from the sides.

\section{Vickers Hardness test}

The Vickers hardness tests were conducted on three regions specified before i.e. worn, unworn and end of the wear track surfaces and the results are shown in Fig. 4 (b). It was found that the hardness is higher located at the end of wear track compared to the worn and unworn surfaces and increases according to the increasing number of cycles. At the end of wear track shows a black spot and it was expected as a plasticity deformation. Analysed by Vickers Hardness data, the value shows high value at this black spot and suggesting plasticity deformation occurred. Parameter for 20 cycle experienced extra cycle compared to 10 cycle and these caused greater plastic deformation due to the extra accumulation at the end of wear track during the reciprocating sliding wear test.

\section{Conclusions}

The following conclusions can be made.

1. According to observed results, the COF is recorded in low value which is in range 0.3-0.4. Different contact pressure shows relatively slight data, rising in a peak at $1 \mathrm{~s}$ for both size of pins and kept maintain continuously. It was found to be stable over the entire sliding distance.

2. Both contact pressures arise a distinguish data for wear width of the wear track. $\varnothing 6.5 \mathrm{~mm}$ of pin exhibited a bit wider compared to $\varnothing 12 \mathrm{~mm}$ of pin. It was due to contact area of the contact pressure is smaller, related to distribution of load on bigger contact area thus lower contact pressure. 3. The hardness value shows the evidence in presence of plastic deformation. It was increases by $40 \%$ from unworn to worn surfaces and the hardness value of the unworn surface increases by as much of $66 \%$ with increasing number of cycles. It is suggesting greater plastic deformation due to higher frictional force and increasing to the number of cycle.

\section{Acknowledgement}

The authors acknowledge the financial support by the Universiti Tun Hussein Onn Malaysia (Research Acculturation Grant Scheme No. R011).

\section{References}

[1] S. R. Chauhan, K. Dass, Dry Sliding Wear Behaviour of Titanium (Grade 5) Alloy by Using Response Surface Methodology, Advanved In Tribology, Hindawi Publishing Corp., India, 2013, pp. 9.

[2] L. Faure, B. Bolle, S. Philippon, C. Schuman, P. Chevrier, A. Tidu, Friction Experiments for titanium alloy tribopairs sliding in dry conditions: Sub-surface and surface analysis, Tribol. Int., 54 (2012) 17-25.

[3] A. Molinari, G. Straffelini, B. Tesi, T. Bacci, Dry sliding wear mechanisms of the Ti6Al4V alloy, Wear, 208 (1997)105-112.

[4] R. S. Magaziner, V. K. Jain, S. Mall, Wear characterization of Ti-6Al-4V under frettingreciprocating sliding conditions. Wear, 264 (2008) 1002-1014.

[5] A. Kapoor, F. J. Franklin, Tribological layers and the wear of ductile materials. Wear, 245 (2000) 204-215.

[6] A. L. M. Tobi, J. Ding, G. Bandak, S. B. Leen, P. H. Shipway, A study on the interaction between fretting wear and cyclic plasticity for Ti-6Al-4V. Wear, 267 (2009) 270-282.

[7] D. Harun, A. L. M. Tobi, A. Singh Chaal, and R. Md.Nasir, "Characterisation of plasticity response for reciprocating sliding wear test of Ti-6Al-4V under variables normal load. Presented in ICXRI Conference, JB, 11-13 Ogos 2014

[8] E. O. Ezugwu, Z. M. Wang, Materials Titanium alloys and their machinability, Journal of Materials Processing Technology, 68 (1997) 262-274. 
[9] Y. Luo, L. Yang, and M. Tian, "Influence of Bio-Lubricants on the Tribological Properties of Ti6A14V Alloy,” J. Bionic Eng., vol. 10, no. 1, pp. 84-89, Jan. 2013.

[10] Y. Chen, T. Cheng, and X. Nie, "Wear failure behaviour of titanium-based oxide coatings on a titanium alloy under impact and sliding forces," J. Alloys Compd., vol. 578, pp. 336-344, 2013.

[11] Y. Luo, L. Yang, and M. Tian, "Influence of Bio-Lubricants on the Tribological Properties of Ti6Al4V Alloy," J. Bionic Eng., vol. 10, no. 1, pp. 84-89, Jan. 2013.

[12] K. L. Johnson, "Contact mechanics and the wear of metal,"Wear, vol. 190, pp. 162-170, 1995.

[13] A. L. M. Tobi, J. Ding, G. Bandak, S. B. Leen, and P. H. Shipway, "A study on the interaction between fretting wear and cyclic plasticity for Ti-6Al-4V," Wear, vol. 267, pp. 270-282, 2009.

[14] R. S. Magaziner, V. K. Jain, and S. Mall, "Wear characterization of Ti-6Al-4V under fretting-reciprocating sliding conditions," Wear, vol. 264, no. 11-12, pp. 1002-1014, May 2008.

[15] M. Mieaniqur-phyriquc, S. Fouvry, P. Kapsa, H. Zahouani, and L. E. O. Vincent, "Wear analysis in fretting of hard coatings through a dissipated energy concept," Wear, vol. 1648, no. 96, 1997.

[16] N. M. Everitt, J. Ding, G. Bandak, P. H. Shipway, S. B. Leen, and E. J. Williams, "Characterisation of fretting-induced wear debris for Ti-6Al-4 V," Wear, vol. 267, no. 1-4, pp. 283-291, Jun. 2009. 